\title{
Endometrial Endometrioid Adenocarcinoma, Variant with Squamous Differentiation
}

National Cancer Institute

\section{Source}

National Cancer Institute. Endometrial Endometrioid Adenocarcinoma, Variant with

Squamous Differentiation. NCI Thesaurus. Code C6290.

An endometrioid adenocarcinoma of the endometrium showing squamous

differentiation. 